\title{
Braiding Designs for Decolonizing Research Methodologies: Theory, Practice, Ethics
}

\author{
Heather E. McGregor heather.e.mcgregor@gmail.com \\ University of Ottawa \\ Brooke Madden bmadden@ualberta.ca \\ University of Alberta \\ Marc Higgins marc1@ualberta.ca \\ University of Alberta \\ Julia Ostertag julia ostertag@yahoo.ca \\ Independent Scholar
}

\section{Abstract}

Describing methodological design in decolonizing research as the intersection of theory, practice, and ethics, we share four focused micro-stories from our respective research projects. The metaphor of braiding represents the methodological design process within each of our research stories, significantly influenced by Dwayne Donald's (2012) Indigenous métissage. Heather grapples with notions of reciprocity, Brooke considers the role of place in the construction of teacher identity, Marc engages with reworking photovoice, and Julia brings relationships with plants into her methodological design. Intentionally interrupting each other and ourselves, we feature the moments and movements of research design that are iterative, recursive, messy, and sometimes stuck, in contrast to the linear, untainted and dogmatic methodologies that assert themselves around us. Meanings and relationships may be produced in braiding our micro-stories together, exceeding what might be possible if they were presented separately. Readers may be invited into imagining the design of decolonizing methodologies beyond those we enacted.

Key words: decolonizing, research methodologies, design, ethics, Indigenous métissage 
Braiding Designs for Decolonizing Research Methodologies 2

\section{Introduction}

We understand methodological design in research as the intersection of theory, practice, and ethics. We are interested in keeping theory "close" in the process of methodological design-braiding instead of bifurcating theory from practice and ethics. In other words, rather than separating one's theoretical framework, application of methodology, adherence to ethical principles, and representation of research findings, we suggest what matters are the intersections and relationships among them. We attend closely to the moments and movements in which this intersection and relationship occurs. Our shared, and sometimes differently interpreted, commitment is to what we understand generally as decolonizing research methodologies. Our respective research projects differently consider aspects of Indigenous education within K-12 or post-secondary institutions in Canada. We are interested in working with Indigenous theories to make visible, and challenge, Eurocentric and colonial assumptions, practices, and structures that often guide research methodologies. We look to explore creative possibilities for qualitative research that supports ongoing processes of decolonizing within and beyond education institutions.

This paper offers four focused micro-stories. Each story is about the ways we have tried to bring into alignment our theoretical and ethical commitments to decolonizing, and the associated unravelling, untying, tucking in, or interweaving along the way. We show how attending to the braiding of theory, practice, and ethics affects how research is produced and what research produces. We do so because we are concerned about the possibility of stating decolonizing intentions as researchers, and then uncritically adopting methodologies and methods shaped through and enacted within the academy's colonizing relations with Indigenous peoples and places. We hope to deconstruct and reconstruct methodological design as a site in which ethical relations can-and must-be pursued.

The metaphor of braiding represents the methodological design process within each of our research stories, and we use it to shape how our stories come together and pull apart. This approach has been significantly influenced by Dwayne Donald's (2012) Indigenous métissage. Recognizing it is a research sensibility "against prescribed method" that "requires dedication to the reciprocating interpretive process and attentiveness to the insights that arise from it" (p. 544), we align with Indigenous métissage in drawing out the situatedness of the researcher and their engagement with theory, practice, and ethics that responds to a particular research context. Donald (2012) advocates for research deeply imbued with a sense of place, and in relation to the Indigenous lands and lives to which research is accountable,

Doing Indigenous Metissage requires work with artifact, place, and context in the hope that a story will emerge that will need to be told. To weave this story requires a provocative juxtaposition of Aboriginal and Canadian standpoints to bring about a shift in the critical consciousness of writer and reader, storyteller and listener. Such relationality needs to happen in theory because it has not been perceived and appreciated in the daily interactions and practices of living together in this place we call Canada. It has been concealed by colonial frontier logics. We must first reread and reframe colonial constructs in order to see more clearly the language and logics that have clouded our thinking. Such theorizing will help deconstruct the colonial frontier logics of inside/outside and facilitate meaningful reconstruction through curricular and pedagogical engagements that traverse perceived civilizational divides. Only then will the stories linking Aboriginal peoples and Canadians revitalize relationships with a common sense of place. (p. 549)

The braiding of our stories may not, at first, seem to convey this purposeful "provocative juxtaposition of Aboriginal and Canadian standpoints" (p. 549). Looking closely though, we hope readers will see that as researchers participating in the academy and diverse sites of institutionalized Indigenous education, we

Reconceptualizing Educational Research Methodology 2018, 9(2) $\quad$ http://journals.hioa.no/index.php/rerm 
are constantly surrounded by colonial frontier $\operatorname{logics}^{1}$ and inspired by Indigenous forms of resistance and revitalization. Even the most taken-for-granted aspects of research methodology warrant rereading, reframing, deconstruction/reconstruction, and traversing with decolonizing commitments in mind.

By featuring the moments and movements in which we differently pursue methodological shifts, and by intentionally interrupting each other and ourselves, we convey our experience of designing research as iterative, recursive, messy, and sometimes stuck, in contrast to the linear, untainted, and dogmatic methodologies that assert themselves around us. We hope meanings and relationships may be produced in braiding our micro-stories together that exceed what might be possible if they were presented separately, and that readers may be invited into imagining the design of decolonizing methodologies beyond those we enacted.

In this paper Heather grapples with notions of reciprocity, Brooke considers the role of place in the construction of teacher identity, Marc engages with reworking photovoice, and Julia brings relationships with plants into her methodological design. Each author shares a research micro-story. We call them micro-stories because they do not, and cannot, offer the full context or description of the research project and its entire theoretical, methodological, or ethical situation. Rather, we have chosen to focus on moments and movements that other researchers might find resonant or relevant with choices they have made or might make in designing decolonizing research.

Each of these stories pulls on three strands. Strand 1 is the theorist and theory each author has chosen to advance decolonizing research methodologies. Strand 2 is the methodological fabrics or specific research contexts from which the researcher designs their process of braiding. Strand 3 offers the braiding inquiries, wherein methodology is braided, rebraided, or unbraided, or all three, depending on our decolonizing approaches. We each conclude our stories with a glance at the braid that was produced. We respond differently to the unique situated relationships that produce, and are produced by, both research and researcher. In this braiding of our research considerations, we collectively attend to the role of theory within these relations, with a focus on how it actively shapes decolonizing methodologies at multiple braiding nodes.

\section{Strand 1: Theorist and Theory Chosen to Advance Decolonizing Research Methodologies}

\section{Marc: Nakata and the Cultural Interface}

A persistent theme and commitment in the decolonizing sensibility I endeavour towards is an ethics of dialogue (see Bohm, 1996; Ermine, 2007). First this entails resisting the dialectic subsuming, sublating, or suturing over of Indigenous ways-of-knowing and -being by Western epistemologies and ontologies that play out through colonial frontier logics. Second, engaging in the dialogical interfacing of these ways-of-

\footnotetext{
${ }^{1}$ Donald's (2012) definition of "colonial frontier logics" entails "epistemological assumptions and presuppositions, derived from the colonial project of dividing the world according to racial and cultural categorizations (Willinsky 1998), which serve to naturalize assumed divides and thus contribute to their social and institutional perpetuation" (p. 550). The "frontier," in the context of contact between Indigenous and European peoples in North America, implies assumptions around land ownership and use, pursuit of progress and entrenchment of capitalism that accompany the racial and cultural categorizations mentioned above.
} 
knowing and -being fosters the possibility of differentially and ethically enacting the Indigenous-nonIndigenous relations that are always already becoming.

It is for these reasons that I am drawn to Torres Strait Island scholar Martin Nakata's (2007a, 2007b) theory of the "cultural interface" to consider the space between Indigenous and Western thought as a methodological site of possibility for, and in need of, an ethics of dialogue. Nakata (2007a) defines the "cultural interface" as "a multi-layered and multi-dimensional space of dynamic relations constituted by the intersections of time, place, distance, different systems of thought, competing and contesting discourses within and between different knowledge traditions, and different systems of social, economic and political organization" (p. 199). Nakata's theorizing of the cultural interface is primarily explored through the perspective of Indigenous learners: "Indigenous learners are already familiar with the complexities of the cultural interface" (2007b, p. 13). However, this familiarity does not make the lived experiences of Indigenous peoples simple or uniform, rather, they are complex, contradictory, and differentially affect Indigenous bodies.

Nakata's (2007a, 2007b) theoretical concept is generative when considering how Indigenous and Western systems both collide and collude with one another in producing diverse bodies, including my own (see Higgins, 2011; 2014a). As a white, male, fourth generation Euro-settler of Irish and Scottish descent working to honour my ever shifting relationships as a science educator working with/in diverse First Nations, Métis, and Inuit communities², I turn to McGloin's (2009) extension of the cultural interface to non-Indigenous learners. McGloin (2009) positions the cultural interface for those who identify as non-Indigenous as "a place of negotiation where for the most part, unlearning can occur, and new knowledges are given primacy" (p. 39). McGloin (2009) posits that, for non-Indigenous scholars such as myself, the non-linear learning at the cultural interface "asks us to consider what we don't or more importantly perhaps, cannot understand" (p. 41, emphasis in original).

My learning and unlearning begins from a recognition that I am advantageously positioned within the diverse, yet entangled, mutually exclusive binary relations that produce and reproduce assimilation, devaluation, appropriation, and erasure of Indigenous peoples, places, and protocols (e.g., settler/Indigenous, culture/nature, civilized/savage, contemporary/traditional). However, simply reversing colonial binaries and binary relations does not always produce decolonizing possibilities. It often engenders a different, yet connected, set of colonial problematics under the name of decolonizing (see Donald, 2012; Higgins, Madden, \& Korteweg, 2015; Nakata, 2007a, 2007b). I resist and refuse the either/or of colonial frontier logics through which colonizing and decolonizing are constructed as mutually exclusive, as this masks the slippage between them. Rather, I engage within and against complex and contradictory de/colonizing spaces of the interface.

\section{Brooke: Cajete's Ecology of Indigenous Education}

I look to advance a decolonizing research methodology founded in an Indigenous ecology of relationships. Of significance in my design is the recovery of other-than-human agents and agency in the flow of discourse, including processes of subjectification. My interest in colonial logics, and how they often organize subjects according to an insider/outsider binary, stems from learning about my Indigenous ancestry as an adult, largely within an Indigenous and allied university community. In

\footnotetext{
${ }^{2}$ As the result of much geographical movement over the last decade, these include: Mi'kmaq and Woolastookiyik communities, Anishinaabe communities, Inuit communities, as well as other First Nation, Métis, and Inuit groups in both urban and rural contexts.
} 
negotiating new alignments between ancestry, identity, and membership, I encountered the systemic productions Donald (2012) speaks of, making one feel they must “...choose sides, to choose a life inside or outside the walls of the fort" (p. 534, emphasis in original). For example, I was advised by some to remain distinctly inside the fort (i.e., identify as a non-Indigenous settler). I maintain that such instruction further obscures my family's colonial histories and positioning, seeks to sever relationships with ancestors and land, and does little to work towards Donald's (2012) call for "complex understandings of human relationality that traverse deeply learned divides of the past and present" ( $p$. 534).

Here, I braid Cajete's (1994) ecology of Indigenous education into my methodological design to explore the relationships between place and the ways that teachers fall short of, imperfectly inhabit, transform, and rupture the prevailing subject positions of teacher in Indigenous education (e.g., Indigenous teacher as 'cultural expert', Madden, 2017). In particular, I draw on two "schematic cues" (Jackson \& Mazzei, 2012) - theoretical concepts with which to design and deliberate-as I reconstruct interview methods, provoke new analytical questions, and generate research productions.

The first cue is the co-constitutive and co-creative relationship between humans and place. Cajete (1994) stresses, "Ultimately, there is no separation between humans and the environment" (p. 84). He details the ways in which physical and psychological characteristics are formed over generations through relationships with unique climates, topographies, and ecologies. But, he argues, "People make a place as much as a place makes them. Indian people interacted with the places in which they lived for such a long time that their landscape became a reflection of their very soul" (p. 84).

The second cue is the "ecological connection of human learning" (Cajete, 1994, p. 218) from which tribal teaching and learning are natural outcomes. Tribal education is intertwined in the daily activities of learners in close communion with living place. The parameters of the school are reconfigured and curriculum emerges from "those understandings, bodies of knowledge, and practices resulting from direct interaction with the natural world" (p. 39). ${ }^{3}$ The ecological connection of human learning invites attention to how living place plays a vital role in teachers' lives and learning.

I wondered: What places do teachers recognize as significant, particularly with respect to developing a sense of professional identity? How are these living places agential in constructing differential bodies of learning in university- and school-based Indigenous education? and How do these places of learning generate productions of meaning, including understandings of self as teacher?

\section{Julia: Barad and Decolonizing Posthumanism}

As a garden-based educator working in teacher education, the theoretical threads of my arts-based doctoral research sought to imagine "becoming teachers together" (Ostertag, 2015) as a relational practice, rather than one framed by the solitary, autonomous, walled-in, enclosed figure of the human Teacher that remains pervasive (see for example Britzman, 2003). Through an installation series at The Orchard Garden, a university campus teaching and learning garden, I sought to entangle teacher becomings, including: my journey as a teacher educator; the experiences of student teachers; and, the land and its co-constitutive parts (particularly plants) as more-than-human teachers. These theoretical commitments - to displacing anthropocentric teacher identities-are partly shaped by Karen Barad's

\footnotetext{
${ }^{3}$ I would suggest that in referencing "the natural world", Cajete does not make a cut between nature/culture or romanticize nature through its relegation to the past. Instead, he theorizes the ways that the natural world and culture shape one another in both traditional and modern education.
} 
(2003) posthumanist call for an onto-epistemology to muddy constructivist accounts by which culture (or theory or epistemology or discourse) is an external force that acts upon passive nature (or methodology or ontology or matter). In recognizing that practices of knowing and being are mutually implicated, Barad's (2003) posthumanist performativity not only suggests a theoretical stance that "calls into question the givenness of the differential categories of 'human' and 'nonhuman'" (p. 808) but also offers a methodological challenge to "[examine] the practices through which these differential boundaries are stabilized and destabilized" (p. 808). In a garden with student teachers, and with particular plants as coteachers and co-researchers, I set out to examine practices that shape the boundaries between human and more-than-human teachers.

I studied these land-based pedagogies as a guest on the traditional, ancestral, and unceded territory of the Musqueam First Nation. As a German-Canadian settler, I was unsettled by, and continue to struggle with, remaining accountable to Indigenous scholarship and decolonizing efforts that connect the academy with larger movements. Particularly considering the notable contributions of Indigenous scholars to understanding human/nature relations (as expressed by Brooke elsewhere in this article, and Sundberg, 2003), the marginalization of Indigenous scholars and scholarship and often unacknowledged relations with First Nations community members in the academy continues to decentre Indigenous knowledge. Perhaps the difficulty lies with what Rauna Kuokkanen (2007) describes as the academy's "epistemic ignorance" that makes it hard to "even grasp or hear views that are grounded in other epistemic conventions" (pp. 2-3). Inasmuch as I wish to avoid such limitations, I am inevitably subject to them myself. Therefore, I strive to maintain an "analytical separation between posthumanist theory and Indigenous epistemes even as there may be overlapping themes and goals" (Sundberg, 2014, p. 34).

Rather than overcoming incommensurabilities or potentially misappropriating diverse Indigenous knowledge practices, I linger beside (Sedgwick, 2003) these differences and begin the humble act of explaining myself. Okanagan scholar Jeannette Armstrong (as cited in Regan, 2010) writes of this act of 'explaining myself' through the language of gardening:

Imagine how you as writers from the dominant society might turn over some of the rocks in your own garden for examination. Imagine ... courageously questioning and examining the values that allow the de-humanizing of peoples through domination.... Imagine writing in honesty, free from the romantic bias about the courageous 'pioneering spirit' of colonialist practice and imperialist process. Imagine interpreting for us your own people's thinking towards us, instead of interpreting for us, our thinking, our lives, our stories. (pp. 234-235)

By turning over the rocks in my own garden, I attempt to recognize that Indigenous knowledge systems are not the objects of non-Indigenous research. Rather, I move towards "the decolonizing project [that] reverses this equation, making Western systems of knowledge the object of inquiry" (Denzin, 2008, p. 439 ) in order to continue unsettling and reimagining the relationship between Indigenous and nonIndigenous ways of knowing and being. Eve Tuck and K. Wayne Yang (2012) describe this situation as abandoning the settler longing for commensurability and attending to the uncomfortable spaces of an ethic of incommensurability as part of "the hard, unsettling work of decolonization" (p. 4).

Through Barad's posthumanist theorizing and Indigenous knowledge practices, my arts- and gardenbased research opened up, and attended to, practices of teaching in and with the more-than-human. However, it would be the unruly presence and gift of fireweed that would begin to teach me just how hard, heavy, and settled the colonial rocks can be in gardening, teaching, and researching practices, as well as in my relationships with land and Indigenous peoples. 


\section{Heather: Kirkness \& Barnhardt's Reciprocity}

Verna J. Kirkness and Ray Barnhardt's 1991 article "First Nations and Higher Education: The Four R's-Respect, Relevance, Reciprocity, Responsibility" is one of the first and most influential articles on university reform to benefit Indigenous peoples. I looked to learn from Kirkness \& Barnhardt about doing university- and community-recognized research, while maintaining decolonizing commitments. Their third " $\mathrm{R}$ " - reciprocity - sparked my curiosity and held my attention. Drawing on Indigenous theory, I hoped to learn how to attend to reciprocity closely, continuously, and comprehensively. Perhaps in braiding my doctoral research methodology I could use reciprocity like a ribbon, against which I could "match" the selection of methods and consideration of ethics.

My pursuit of reciprocity would be situated with many contextual factors stemming from the distinctiveness of researching in Nunavut (McGregor, 2015), the place I view as "home," balanced with participating in the academy where scholars often work to highlight shared and common Indigenous commitments (such as the four R's). Not the least of these significant factors is the specific ways my claims to identity shift among markers such as settler, Northerner, Qallunaaq ${ }^{4}$, non-Indigenous ally and recipient of systemic privilege when read as "white," and how those shifts carry different meanings in different situations.

Not intending to adopt Indigenous research methodologies, but to learn how to adapt ideas from them to my own research situation, I began with the question: What is reciprocity and what does it ask of researchers, according to Indigenous scholars (see also McGregor \& Marker, in press)? Briefly put, I found that Kovach (2009) equates reciprocity with "giving back." Archibald (2008) describes reciprocity as sharing knowledge and teaching, or participating in an intergenerational process called "hands back, hands forward." Marker (2004) highlights reciprocity in terms of preparing oneself to receive knowledge by doing something meaningful with the knowledge holder from whom one will learn. Rauna Kuokkanen (2007) differentiates Indigenous views of reciprocity from Western ones by referring to them as taking a "circular form." It is not for the accumulation of gifts or insurance of countergifts later on, as in the modern economy, but rather to keep gifts circulating, to "actively acknowledge kinship and coexistence with the world" (p. 38). Kuokkanen (2007) explains: "This kind of reciprocity implies response-abilitythat is, an ability to respond, to remain attuned to the world beyond oneself..." And she argues, "the gift is a continuous process and practice of reciprocation, recognition, and negotiation without closure" ( $p$. 154).

With these teachings, I found that Indigenous conceptualizations of reciprocity exceed a "give-and-take" approach that can be achieved through transactional, measurable, direct, and time-limited compensation. By extension, it is too limiting to associate reciprocity with the simple idea of giving participants a gift at the end of research.

However, with the more holistic conceptualization of reciprocity offered by Kuokkanen, other challenges emerge. For example, how might local protocols or gift giving ceremonies of reciprocity need to be adapted to account for the identity of the researcher? What if academic institutional regulations prevent those protocols, as Marker (2004) has noted in his scholarship? What is to be done and said if and when reciprocity becomes an impossibility-when researchers simply cannot give back in equal measure what was given to them?

\footnotetext{
${ }^{4}$ The term used by Inuit to refer to people in Nunavut who do not have Inuit ancestry, usually (but not exclusively) those of European descent.
} 


\title{
Strand 2: The Methodological Fabrics or Specific Research Contexts from Within Which the Researcher Designs their Process of Braiding
}

\author{
Julia: Gift Giving with Fireweed
}

Fireweed entered my year and a half-long site-specific installation series, Threads sown, grown \& given $n^{5}$ as a gift to land (i.e., Threads given) in response to settler colonialism and other socially- and ecologically-oppressive discourses and practices. ${ }^{6}$ The fireweed, like the flax I planted before it for the installation, extended posthumanist theoretical explorations into "becoming teachers together" with plants, and ongoing experimentation with the practices of more-than-human research methodologies (Whatmore, 2006). It also reflected what I learned from Indigenous scholar Rauna Kuokkanen's (2007) description of gift-giving practices that generate intricate relationships, "reciprocation with and responsibility toward all others" (p. 7). Kuokkanen (2007) explains how Indigenous gift-giving practices unsettle the colonial and increasingly neoliberal academy. ${ }^{7}$ However, I recognized that Indigenous giftgiving practices are usually enacted within knowledge traditions, relations, and protocols in which I had not been mentored, or might not be mine to follow. Rather than mis/appropriate Indigenous practices, I attempted to hold open a creative space for something to arrive that would feel appropriate in the particular conditions of my research.

The idea of fireweed arrived in the rainy winter months while I sat, quiet as a spider, spinning flax to linen with a wooden drop spindle in the basement of the teacher education building. Flax is a plant of straight lines (linum usitatissimum, the very useful line or linen), whereas fireweed is as its name suggests: a weed that spreads via hundreds of thousands of seeds that drift in the wind-as well as underground through rhizomes. And yet, fireweed is edible, medicinal, beautiful, and can be spun as a fibre plant. Bees and other insects love fireweed blossoms, and it is known as a plant of regeneration, growing after fires, deforestation, even bombings (e.g., in England it is known as bombweed).

Fireweed is also a colonizer-a pioneer plant that rapidly proliferates in disturbed soils. It provokes unsettling material conditions that threaten settler notions of decolonization as a metaphor (Tuck \& Yang, 2012), since the repatriation of Indigenous relations with land is pivotal for any movement toward reconciliation. Fireweed also disrupts the settler belief "that land can be owned by people, and that occupation is a right, [which] reflect[s] a profoundly settling, anthropocentric, colonial view of the world" (Tuck \& Yang, 2012, p. 24). To intentionally plant fireweed in a garden unsettles the notion of what belongs in a garden and who is in control, providing the kind of decolonizing research method I was seeking theoretically. Methodologically and ethically, gift-giving with fireweed implicated me in the lives of more-than-human others (e.g. garden, fireweed) as well as entangling me in the ethical engagements and responsibilities (Kuokkanen, 2007) that gift-giving entails.

This ethical stance, however, was put to a test. Prior to planting fireweed, I met with the student gardeners with whom I collaborated to discuss my plans for the final installation. One student found my

\footnotetext{
${ }^{5}$ To see a time lapse of the outdoor aspects of this installation series, see: http://hdl.handle.net/2429/52953 or view my research blog posts at http://theorchardgarden.blogspot.ca/search/label/Installation

${ }^{6}$ My research into school gardens was particularly concerned with oppressive ideologies and discourses twinning education and agriculture. As a German-Canadian, I focused on the use of gardening in the Indian Residential School system and during Nazi Germany as two compelling examples of school gardening that required-or compelled (Simon, 2006) - a response.

${ }^{7}$ Heather and I were part of a self-directed reading group on gift giving and reciprocity during one year of our doctoral research
} 
plan, and this plant, highly threatening in a food production garden: "I do think this use of the weeds ties into your themes really well...but...I'm very scared of them. I'm so scared that next year we'll have fireweed everywhere. And then we'll curse your name." In order to appease my human gardening colleagues, I made a terrible promise: I would cut the fireweed blossoms before they went to seed and only allow the plants' rhizomes to slowly spread underground.

\section{Brooke: Learning to Teach and (Un)Becoming Teacher in British Columbia} My research is woven into the emergent and complex movement to decolonize and Indigenize Faculties of Education and schools across the province of British Columbia. Programmatic, curricular, and policy reform contribute to nurturing and mobilizing Indigenous knowledges, advancing Indigenous leadership through recruitment and retention, and improving Indigenous-non-Indigenous relationships.

For example, all members of the Association of BC Deans of Education committed to including a required course in Indigenous education (or equivalent) by 2011 in their respective teacher training programs. The provincial Ministry of Education is in the process of a $\mathrm{K}-12$ curriculum redesign that draws heavily on First Peoples Principles of Learning. As of June, 201654 of 60 school districts in BC have worked with local First Nations to draft Aboriginal Education Enhancement Agreements. I suggest that such initiatives often position teachers at the centre of their operation, particularly those who are early in their career and have completed formal coursework in Indigenous education during their teacher training.

My study examines how transition between Faculties of Education, schools, and areas between (e.g., teaching practicum) shapes and supports teachers' emerging professional identities and practices. The experiences of nine Indigenous and ally early career teachers who participated in university-based coursework and, in some cases, extended professional development on the topic of Indigenous education are the focus. Teachers participated in a series of three individual, semi-structured interviews organized by topic: 1) teachers' personal-professional identity, 2) teachers' experiences of participating in teacher education on the topic of Indigenous education, and 3) teachers' relationships with place revealed through walking interviews. Seven teachers also participated in an optional interview where they shared a lesson or unit they developed that integrated Indigenous content.

Here, I focus on how a walking interview was designed to "take indigenous thought seriously" (HaigBrown, 2008) through centring the oft-overlooked role of place in indigenous education in general, and learning to teach and becoming teacher spesifically. Braiding with schematic cues from Cajete's ecology of Indigenous education produced the conditions for actors, senses, responses, and modes of storytelling to emerge that may not otherwise manifest in seated interviews.

\section{Heather: Interviews with Government Staff about Processes of Decolonizing}

The methodology I imagined for my research involved talking with people about how to enact Indigenous education within a formerly colonizing school system. With decolonizing commitments shaping the theoretical framework, my research intention was to document the recent history of educational change in Nunavut-Canada's northernmost, largest and most geographically dispersed jurisdiction. Nunavut is home to a relatively sparse population, the vast majority of whom are Inuit. When their Arctic homelands were appropriated by the Canadian State, the Inuit who lived there became subject to fast and intense processes of colonization.

Nunavut has recently undergone formal processes of decolonizing. That is, legal agreements and political mechanisms have been established to return rights and devolve powers to Inuit. Nunavut's public government, in 2008, passed legislation requiring that all public schools place Inuit language and culture at the centre of their programs. This entails significant goals for decolonizing schools. 
Despite the primacy given to Inuit identity, culture, and language in government policy, including public schools, the practices of the public government still carry Eurocentric roots that often circumscribe or slow change. This continues to shape relations between Indigenous and non-Indigenous people. Therefore, Nunavut is a context deeply affected by ongoing processes of decolonizing.

In this context, I hoped to invite government employees who work for the department of education into my research, focused on their curriculum development, policy, and leadership projects. This could involve both Inuit and non-Inuit participants who might volunteer. I had formerly worked with, or otherwise knew, all of these individuals. Indeed, one of these people was my mother, Cathy. Seeking to conduct interviews or a focus group with these potential participants, I began to ask myself how this design could "match" with the ribbon of reciprocity that was emerging through learning from Indigenous scholars?

Several conditions affected my pursuit of reciprocity. The first was that the prospective participants were government staff members. I was seeking to interview them on government time, as part of my view of reciprocity: this research should not take time away from their families. Any gifts I offered them would have to fit with what was permitted by the government. Secondly, they were experienced, knowledgeable and highly capable professionals. With full-time jobs, they were unlikely to benefit significantly from a small monetary recognition of their time, and-while I do not know this for sure-I wondered if they would be unlikely to accept a form of return of service from me, rather just wanting to "help out." Lastly, Inuit do not share in some of the cultural protocols more common to First Nations elsewhere in Canada, such as giving tobacco, which may have been frowned upon by the university research ethics board anyway. How could I take up Kuokkanen's imperative to "response-ability" under these conditions and find forms of reciprocity that would be enough to honour the relationships that would make my research possible?

\section{Marc: Methodology and/at the Cultural Interface}

While I understand the cultural interface as a productive conceptual and lived location from which to explore decolonizing methodology, I wondered, what would it mean to also consider methodology as a "body" located at, and produced by, the interface (see Higgins, 2014b)? How could a methodology account for and be accountable to "what can be said or not said, heard or not heard, understood or misunderstood, what knowledge can be accepted, rejected, legitimized or marginalized" (Nakata, 2007a, p. 199)?

My current research centres a science education pedagogical project in which youth visually storied their relationships to Nature (i.e., space, time, matter; see Higgins, 2016). Considering culture and cultural fluidity in how we come-to-knowing with/in nature has always been an important facet of decolonizing science education that resists the either/or of nature/culture (Aikenhead and Michell, 2011; McKinley, 2007). I also aim to take Indigenous notions of natural-cultural interconnection seriously (Cajete, 1994, 1999). I do this by accounting for and being accountable to the diversity of participants at the cultural interface. For example, participants in this project primarily included middle school students who are often identified as "new Canadians" and "English as an Additional Language" (EAL) learners from diverse parts of the world (e.g., Asia, Middle-East), a Cree-Métis collaborating teacher, and myself as a Eurosettler educator-researcher. These individual and collective interfaces come to include the natural and cultural flux of the here-now, as well as elsewheres and elsewhens-past, present, and futurities-tocome-that shape us as well. The school where the project took place is located on the traditional, ancestral, and unceded territories of the Kwikwetlem peoples, which is located within the larger Coast Salish region in what is now referred to as British Columbia. Always already suturing over this school space are the dominant discourses and enactments of Euro-settler society; its past, present, and 
overcoded futurities often explicitly playing out through the school's curriculum and pedagogy. Attention to the spatial organization of the interface also invites consideration of the ways that school spaces (e.g., architecture, desks in rows, teacher at the front of classroom) produce a "Eurocentric curriculum [that] is hidden in plain view" (Battiste, Bell, Findlay, Findlay, \& Henderson, 2005, p. 8).

I looked to visual methods to critically inhabit this location and pedagogically explore and facilitate the possibility of ethical dialogue at both personal and collective interfaces. I argue that visual methods lend themselves to this type of work as they center "an individual's complex, complementary, and conflicting points-of-viewing the world" (Higgins, 2014a, p. 158). Further, they provide a potentially rich point from which to reconfigure and resist diverse dualistic colonialisms (e.g., nature/culture, individual(ism)/collective, mind/body).

To ground the science education pedagogical project, I employed the predominant visual method used within education and the social sciences: photovoice. In short, photovoice "is a process by which people can identify, represent, and enhance their community through specific photographic technique" (Wang \& Burris, 1997, p. 369). Photovoice is said to visually amplify participants' agency around matters that are important to them of both personal and communal nature by paving pathways for policy change and resisting problematic representations that negatively position them within society (Lutrell, 2010; Wang \& Burris, 1997). However, as a methodology at and for the cultural interface, it would require reworking.

\section{Strand 3: Braiding Inquiries, Wherein Methodology is Braided, Rebraided or Unbraided, or All Three, Depending on Our Decolonizing Approaches}

\section{Heather: Relationships in Research}

An unexpected challenge occurred as I was considering how to invite department of education staff members to participate in my research, in ways that could match what I had learned about reciprocity from Indigenous scholars. In carefully preparing a behavioural research ethics review board application I explained that my mother was a senior manager in the department through which I would be recruiting participants. Her retirement date was approaching so I noted that to prevent any perception of conflict of interest, staff members my mother had supervised would not be interviewed until after her retirement date.

However, the ethics review board representative expressed concern that "[i]n Nunavut, senior level civil servants often have and/or are seen to have influence beyond their retirement." Therefore, I was asked to address "concern or acquiescence that may be present among other study subjects [sic] as a result of the researcher being related to someone in a position of power and authority."

Initially, I viewed this concern as inflated. Having worked in government with many of the potential participants, I felt confident they would recognize my research project as separate from their relationship with my mother. I thought that knowing the potential participants through pre-existing relationships would favour our ability to come into respectful and reciprocal research relationships in a decolonizing context. However, whether my mother's influence or position would actually play a part in staff deciding to participate in my research was something I would likely never know. Now the potential for a perception of pressure would niggle at me.

\footnotetext{
Reconceptualizing Educational Research Methodology 2018, 9(2) $\quad$ http://journals.hioa.no/index.php/rerm
} 
The suggestion put forth by the research board was to use a blind recruitment process where prospective participants would not know who was recruiting them into research. This felt exceedingly strange in a relatively small community, potentially misleading, and unlikely to lead me into ethical relationality. This was not something that would be well understood or accepted by my former colleagues in this largely Indigenous research context.

I was trying to pursue research that would honour the educators whom I knew were doing good decolonizing work, but the terms of their participation were causing a swirling confusion in me about whose intentions and interests were of most concern. It was like the fabrics with which I was workingthat I thought I knew so well-seemed to be changing colour and shape under my nose, as though someone had thrown them in the washing machine and dryer while I slept. How could I honour my commitment to decolonizing, and my commitment to reciprocity, when what had felt familiar now felt strange?

I realized that pursuit of reciprocity was no simple task of matching fabrics (methods) to the ribbon (theory) in my methodological braid. The changes in the fabrics reminded me that it may not be useful to expect that forms of reciprocity other researchers use will work in my own research situation, or that pre-existing relationships will mean I know what reciprocity looks like, or that I can even expect to actually achieve reciprocity. Taking Indigenous theories of reciprocity seriously, while resisting academic conventions that might undo relationality as I understood it, called me to look deeper at what reciprocity might mean and might produce.

\section{Julia: Risks of Ethical Engagement}

Planting fireweed rhizomes for the Threads given installation came with a promise, but like many promises made in moments of desperation, their unpredictable consequences can haunt a person later. As the fireweed bloomed I fell in love with its ravishing fuchsia flowers, as did hundreds of bees and other insects. I wanted the seeds to fill the garden, and permeate the soil, and drift through the air. I did not want to interrupt the plants and strip them of their seeds, even buoyed by the hope that the remaining underground rhizomes would survive and continue to spread. I wanted to retract my promise to the student gardeners and honour a larger promise I made when I invited fireweed into the garden as a gift.

In this complex moment, the coherence between theory and methodology I managed to braid together was disrupted. The gift of fireweed was unsettling and threatening to my colleagues in the garden. My previous installations (Threads sown \& grown) involved planting flax plants in (beautiful!) rigid grids, which had taught me to recognize student teachers' and my own deeply entrenched desires for order and control-even outside, in "nature", while gardening. Succumbing to pressures for garden conformity, I ultimately fulfilled my promise to cut the fireweed. Sitting inside the circle of fireweed plants and surrounded by the buzzing of dozens of bees, I destroyed my gift; I destroyed the gift of fireweed. As I filled the red wheelbarrow with the cut blossoms, bees trailed after them, continuing to drink nectar as the plants slowly withered.

This was not the only unexpected disruption to my gift giving. During the spring when I planted my fireweed gift, the student gardeners and I learned that The Orchard Garden was slated for destruction the following year, to allow for the construction of a new private international student college on campus. The one-year program would be charging students roughly $\$ 45,000$ to live and study at what, in perfect neoliberal lingo, the campus planners had renamed the Orchard Commons. 
As I gave the gift of fireweed to the land and in response to settler colonialism, my actions became futile in light of the giant neoliberal, colonial, and patriarchal forces driving the academy. I was so angry and hurt by these developments that I felt compelled to quit my doctoral studies in a public spectacle. Instead, I returned to the pile of cut blossoms lying in a wheelbarrow at the garden, gathered them in my arms, and spread the wilting plants along the steps of the campus planners' office and in a large bouquet against the door. This new fireweed gift might have been small and insignificant. But, I hope this unravelling of my braid through a secretive act of rebellion might, as Donald (2012) writes, through "aokakio'ssin or careful attention to the details of the research context," lead to a story "that will need to be told" (p. 544).

\section{Marc: Photovoice at the Cultural Interface}

As Nakata (2007a) states, "it is important to reiterate that the cultural interface is the overlay of myriad intersections of sets of relations and in this sense it is also a theoretical space" (p. 219). Elsewhere (Higgins, 2014b), I take up this call as an invitation to unbraid and rebraid photovoice as a methodology that is both at and for the cultural interface. This took the shape of placing two Western theories that predominantly inform photovoice-feminist standpoint theory and praxis-in conversation with related Indigenous iterations of these theories that are seldom acknowledged or honoured (see also Donald, 2012). Through attending to the ways in which these theories come together and pull apart, photovoice was reworked to account for and be accountable to the patterns of difference that emerge, while resisting the dialectic move to negate either Indigenous or Western ways-of-theorizing.

Four major analytical frames and associated methodological recommendations arose from this braiding. First, other-than-humans (e.g., plants, rivers) and more-than-humans (e.g., spiritual beings) should not only be included for political reasons (e.g., land claims), but also because they are active, important, and oft-neglected members of the ecologies of relationships that shape the cultural interface. Secondly, because other-than- and more-than-humans, like other entangled agents, are always already in relation, the photovoice that is produced at an interface could be considered with rather than about the ecology of relationships. Third, because photovoice is a communicative act, the community of knowers who are both intended and unintended audiences should be considered as entangled within this interface and the voice that arises. Lastly, because of potential readers/listeners' colonizing tendencies to treat Indigenous peoples and knowledges in a doubly problematic and polarizing manner ${ }^{8}$, photographic juxtaposition presents analytic and representational opportunities to momentarily interrupt reading practices sutured over by colonial imaginaries (see also Madden, Higgins, \& Korteweg, 2013). I brought these methodological considerations regarding the cultural interface and decolonizing intersections with me into the process of designing research. I created a pedagogical project wherein new Canadian youth were invited to explore their distinct and layered positions at the cultural interface, through producing their own digital comic books.

\section{Brooke: Walking Interview With/in Significant Place}

Teachers were invited to guide an interview through a place that they connected with developing a sense of teacher identity that is in relation to Indigeneity. When asked to expand on what it means to be

\footnotetext{
${ }^{8}$ Indigenous peoples and knowledges are often asked to align with either Western or an Indigenous position, the latter being read as a pan-Indigenous position of the past to either be romanticized or pathologized. These colonizing frames problematically (re)produce Indigenous peoples and knowledges as uniform and 'knowable', as well as separate from and inferior to their Western counterparts (Donald, 2012; Higgins, Madden, \& Korteweg 2015; Nakata, 2007a, 2007b).
} 
in relation to Indigeneity, I shared that teachers might select a place that supports holism or additional characteristics of Indigenous knowledges and pedagogies. I suggested that we could visit somewhere significant that deconstructs a culture/nature binary-whereby place is either the passive backdrop for, and product of, human activity or romanticized. When choosing a location, teachers were also encouraged to consider Indigenous perspectives that may be incommensurate with the stories they hold of a place.

I requested that teachers, with place, lead the walking interview. However, I shared a set of questions in advance that were intended to support exploration of the generative and relational meaning that is made through movement with/in living place. Informed by Cajete's ecological connection of human learning, the prompts focused on: a) teachers' perceptions of the parameters of place; b) stories of, and interaction with, living place; and c) tribal approaches to teaching and learning and the understandings, sources of (Indigenous) knowledge, and practices that emerge. These walking interviews through significant places typically lasted one hour, and were documented through handheld recorders, photographs, and researcher fieldnotes.

While Cajete provides theoretical frames to consider teacher identity within an ecology of Indigenous education, a wide body of methodological theory supplements my attempts to momentarily and imperfectly 'capture' and portray (un)becoming teacher in significant places. For example, Marin's (2013) scholarship on the coordinated activity of observation during forest walks encourages: mapping movement (e.g., stopping) and noting the references and gestures utilized by humans to relate to living place. Kuntz and Presnell (2012) support reframing interview as intraview - "a process-based, intraactive event,... [that is] a cocreation among (not between) multiple bodies and forces" (p. 733). Intraview as event and Cajete's co-constitutive human-place relationship invite consideration of living place as an agent in the co-production of interview, and the (un)doing of teacher therein.

Through this theoretical-methodological framework, several analytical questions became possible. These questions were asked of interview artefacts (Jackson \& Mazzei, 2014) in attuning to what MacLure (2013) calls "wonder" - "almost literally [data] hot spots, experienced...as intensities of the body as well as mind" (p. 173), as well as co-authoring productions alongside teachers and living places. Despite attempts to structure, respond to, and account for walking interviews, transgressive data (St. Pierre, 1997) hangs provocatively from this braided inquiry like messy dangling threads. Instead of lamenting the shortcomings and slippages of language, in the glimpse at my braid below I invite readers to revel in the agency and entangled nature of place.

\section{A Glance at the Braid: Productions that Result from Braiding with Theory}

\section{Marc: Research Practice at the Cultural Interface}

Leading up to production of comic books at and for the cultural interface, student participants in my research were supported through a variety of activities over the course of a month-long interdisciplinary project. These included photographic skill-building exercises that typically accompany photovoice-based projects (e.g., learning about photo composition and the ethics of photography), as well as a curriculum of aesthetics and techniques for creating digital comic books through Comic Life (see plasq.com). This skill-building curriculum was also accompanied by a series of complementary activities that worked to resist the either/or of colonial frontier logics and centre Indigenous content. These activities included, but were not limited to, the following: developing a language of relationship to account for the diverse 
"natural" and "cultural" bodies we encounter explicitly and implicitly; exploring how complex and contradictory relations of the cultural interface registered on our bodies through individual and collective sensorial-affective observation of both inside (i.e.,"cultural" space) and outside (i.e., "natural" space) the school; spatial mapping to consider how space becomes place; as well as engaging Indigenous storywork (Archibald, 2008) as teachings, medium, and in dialogical interface with comics (e.g., Yahghulanaas, 2009). Furthermore, a local Elder was invited to speak about the territory and some of the relationships therein.

One story produced by a student features a day in the life of a book-The Diary of a Wimpy Kid, a popular young adult fiction novel available in the school's library ${ }^{9}$. The author Danielle (pseudonym) had chosen this book as protagonist to tell her story with, rather than about. Interestingly, books are often regarded as enacting a series of colonial notions. For example, knowledge as a thing-unto-itself that is already made underscores permanence, granting written textuality superiority over orality and conveying the perception that written records are a criteria for achieving "civilization" (see Battiste et al., 2005). Libraries are thus places having many-times-over achieved the "clean" and privileged epistemic break of knowledge that does not require a knower. They thus become both literal and metaphorical centers of Western knowledge that devalue the Indigenous adage that knowledge sits in place (i.e., as it is already sitting, both literally and idly, in the library). Additionally, as this book is part of a multi-million dollar franchise, it is also entangled in economic neo-colonialism.

However, Danielle's telling of the story from the book's perspective (i.e., as an agential author not a passive receptacle of 'knowledge known') centres an other-than-human member within the ecology of relationships that shape her cultural interface. This might be viewed as a productive step towards taking Indigenous thought seriously; honouring that wisdom might sit in place through the contribution and sustained intergenerational learning with other "natural" bodies such as animals, plants, rocks, and rivers (Cajete, 1994, 1999; Nakata, 2007a, 2007b). Furthermore, the book acted as a de/colonizing agent beyond the story told. The Diary of a Wimpy Kid became a relational pivot point for Danielle to converse with the librarian about the everyday life of books despite many books' status as being a self-enclosed source of knowledge (see Higgins, 2016).

How can the digital comic books produced by the new Canadian students be understood as decolonizing? I attempt to read their stories as both/and, or as de/colonizing. This questions the readily available either/or discourse that produces these "new Canadian" youth as either the beneficiaries or victims of an ongoing (neo-)colonial project of a settler nation-state. It also makes space to resist the conditions that deny these youth the possibility of being complex human beings located in-between at the cultural interface.

\section{Julia: Research with Living Beings}

While the gift of dying fireweed blossoms felt like a ridiculous failure, and far cry from what I had imagined "becoming teachers together" or decolonizing would entail, perhaps, as Judith Halberstam (2011) suggests,

Under certain circumstances, failing, losing, forgetting, unmaking, undoing, unbecoming, not knowing may in fact offer more creative, more cooperative, more surprising ways of being in the world [...]. Failure allows us to escape the punishing norms that discipline behaviour and manage

\footnotetext{
${ }^{9}$ For further and differential analysis of this participant-produced, digital-photography-assisted comic book, see Higgins (2016) and (Higgins \& Madden, in press).
} 
human development with the goal of delivering us from unruly childhoods to orderly, predictable adulthood. (pp. 2-3)

I conclude with this failed gift of dying fireweed blossoms because braiding myself into these plants' lives through my research practices matters deeply. Gift giving to the land (Kuokkanen, 2007) implicated me as gardener, teacher, and researcher in ethical relations of responsibility. As such, the activist event at the end of Threads sown, grown \& given mattered not only as a theoretical consideration or to fulfill rigorous methodological requirements. It mattered because the plants and other human and nonhuman participants in my research were not simply metaphors but became lives to think with, to be with in ethical relations, "for they are not merely tools for our use but real living beings" (Barad, 2011, p. 127). Arts-based research practices in particular created the conditions for non-instrumentalist, ethical, and relational research to experiment with my "deep sense that things might be otherwise" (Haraway, 2004, p. 326). Attending to fireweed, as a living presence and a gift, disrupted the familiar ordering of the world and allowed for surprising, unsettling, activist, and even perhaps decolonizing ways to be in the world together, for becoming teachers together.

\section{Heather: Reciprocity as a Stance}

I looked to literature in qualitative research to supplement my reading about reciprocity in Indigenous research. I found Trainor and Bouchard's (2012) conceptualization of reciprocity as a "stance" particularly resonant with Indigenous perspectives, especially Rauna Kuokkanen's term "responseability", and Michael Marker's view that expectations for reciprocity sometimes exceed what institutions allow (McGregor \& Marker, in press). A researcher may attempt to create the conditions for reciprocity to arise by extending invitations, maintaining an open stance towards facilitating negotiated relationships, and taking actions or making changes that respond to relationships as they are enacted. This, however, offers no guarantees.

Part of what was produced in the braiding of my methodological design is an expanding understanding of what it means to take reciprocity seriously in Indigenous education research. I moved from thinking of reciprocity as the ribbon in a braid (to which methods can be matched), to thinking of it as the stance the researcher takes while braiding. This stance is comprised of at least four dimensions, all of which must be interpreted and adapted to fit local conditions (McGregor \& Marker, in press). While the abridged microstory I have shared here does not fully speak to each dimension, they include: 1) Recognizing relationships that make research possible at a particular time and place through offering gifts that have meaning or purpose; 2) Participating in local ways of teaching, circulating or sharing knowledge, and preparing oneself accordingly; 3 ) Enacting response-ability towards others through continuous practices of openness, recognition, and negotiation without closure; 4) Pursuing a stance of reciprocity even while maintaining an awareness of its tenuousness - that a gift could be interpreted as a threat, that a gift might not be accepted, or that a gift will not be enough.

Another production was a substantial change in my methodological design. When it was suggested by the research ethics board that my mother might be viewed as a figure with substantial influence in the context of my research, it occurred to me to position this as an opportunity and strength rather than something to avoid. Combined with several other moments and movements that led to changes in my research methodology, I moved away from interviews or focus groups with a wide range of government employees and instead completed an in-depth career biography interview process with my mother. This, of course, raised another set of questions about what situated reciprocity and a pursuit of ethical relations could mean. Reciprocity, then, shaped the stories I told and the stories I did not tell. 
There are gradations of explicitness in how reciprocity is represented, reported, and enacted in the outcomes of research. The last production of this braiding is an invitation to make reciprocity the focus of critical conversations about research and relationships. I view this as especially important in research that supports decolonizing imperatives, pursued with methodological approaches intended to be consistent with, and advance, those imperatives.

\section{Brooke: Fort Langley and (Un)Becoming Teacher of Indigenous Education ${ }^{10}$}

The teacher who is guiding the walking tour of historic Fort Langley and I emerge from an earthy smelling tower peppered with shadows where absent presences drift and disappear. I step onto the wooden platform that connects the tower ahead with the one behind. Directly to my left are two dozen vertical cedar logs that together form the north wall of the fort. The sun is so mighty, you would never guess that it is January. My nose and cheeks delight as melanin is activated. Rita (a pseudonym) rests her arms on one the middle logs and gazes at the Fraser River:

I'm not really a product of that settler past, nor do I identify with Aboriginal communities... Looking outside of myself at myself, the fact that I have a connection to a place like this is quite bizarre... My values are, um, I find them represented here//in some ways, like not in all ways//but in that sense of cooperation or even what the guide was talking about. Just a lot of stuff that was happening here was based on relationships, on respect, and seeing other people as equals, and seeing things like justice...

A force seems to come from nowhere, from everywhere, one that I am differently, though no better, positioned to explain after multiple listenings to the audio recording. I blurt, "Have you read The Orenda?" We have been walking for almost 40 minutes and I have yet to mention Joseph Boyden's historical fiction novel that is set within, and beyond, a fort and told from the perspectives of a kidnapped Iroquois girl, a Huron Elder, and a Jesuit priest. Why now? What might this outburst signal and how are both Rita's and my words co-constituted with place?

I have marked this as a data hot spot that glows because the physical space that engages sense at the level of affect exceeds the ability to read this interview artefact exclusively as a social text. The positioning of the platform at the highest point in the fort, which itself is located at one of the highest elevations in the village, produces a full, yet removed, view of the Kwantlan First Nation community. The reservation appears picturesque - a shimmering river spotted with rowboats; grassy waterfront backed by a vast forest and snowcapped mountains; a bright white chapel that Rita referred to as "so quaint and beautiful"; a place where "two different kinds of cultures and two types of spiritualities" exist. There is also an 'insider's' view of the fort - evenly spaced buildings organized by function encircle a manicured lawn where elementary school students led by a costumed guide recreate a salmon run.

Other than metaphor, I suggest this place produces, and is produced by, the conditions that enact binary sight. For example, the opposing views support cultural/natural and civilized/primitive binaries and collude in constructing distinct "settler" and "Aboriginal communities" despite the entangled character of the fort. The ability to access only one in-depth perspective-that of the fort-contributes to an insider/outsider hierarchy that may have shaped the guide's earlier claim that, "The lives of First Nations women who married into the fort were considered easier than if they lived in the village... You can imagine what a game changer a pot would have been!" I argue that these material-discursive conditions

\footnotetext{
${ }^{10}$ Consideration of this data fragment in further detail and in relation to distinct schematic cues is taken up in Higgins \& Madden (in press).
} 
function to construct a differential fort-human body of learning, whereby particular settler stories of benevolence are more likely to circulate and stick.

While Rita initially troubles her relationship to the fort based on incompatibility with available markers of identity, she recovers her connection by citing that her values are represented. I question: How are the values of respect, equity, and justice connected to the signified Teacher? How does the fort contribute to the production, organization, circulation, and regulation of the norms of intelligibility that determine what can be said and done? And further still, could (what I regarded at the time as) the counterstories of The Orenda be framed as a gift that held the potential to rupture these normalized fictions?

\section{Conclusion}

Dwayne Donald's decolonizing research sensibility calls for renewal in ethical relations between Indigenous and non-Indigenous Canadians. Individually, and in juxtaposition, our work attempts to "hold together the ambiguous, layered, complex, and conflictual character of Aboriginal and Canadian relations without the need to deny, assimilate, hybridize or conclude" (Donald, 2012, p. 536) in the context of pursuing research. As education researchers, our stories center enacted and embodied relationships and how theory informs our understandings of, and responses to, those relationships.

We follow Donald (2012) in engaging métissage not for the purpose of producing "better" research, or to communicate new and transferable "solutions" for old research problems steeped in settler colonial logics - although we do not rule out those possibilities. Rather, we aim towards showing how "taking Indigenous thought seriously" (Haig-Brown, 2008) necessitates questioning methodological formulae, often in the form of disciplinary conventions, using Indigenous and decolonizing theoretical cues.

We have done so here through four micro-stories, by illuminating moments and movements in the braiding of methodological design, when our decolonizing commitments bring out choices to be made, or responses to be determined. As Donald (2012) suggests, the "textual quality of the braid"[s] emerge as we engage with the specifics of our research contexts, and attend closely to interpreting how our inquiries relate to ethical relationality. We have attempted to sit with these moments and movements rather than skipping over them-or worse, smoothing over them-in order to feature only the products of research, the "findings," as is the case with a great deal of scholarship that we read.

We see decolonizing methodologies as grounded in an ethic of plurality, rather than prescriptions and prohibitions. Plurality emerges out of commitments to relationality, entanglements, and embodiments in place. Therefore, designing and enacting decolonizing methodologies always looks, and is, different. This difference offers strength-not liability. As researchers we can learn from the placed and relational attempts of others who take up different braiding/unbraiding processes, stances, and produce different braids, from their unique positions and locations, using their particular gifts. We invite readers to do the same in their own processes of methodological design - to sit with the intersections of theory, practice, and ethics even when they are not neat and tidy, and especially when they reveal the pervasive possibilities of colonizing and decolonizing relations. We invite readers to braid their research relations differently, and to share their braiding stories. 


\section{References}

Aikenhead, G. S., \& Michell, H. (2011). Bridging cultures: Indigenous and scientific ways of knowing nature. Toronto, ON: Pearson Canada Inc.

Archibald, J. (2008). Indigenous storywork: Educating the heart, mind, body, and spirit. Vancouver: UBC Press.

Battiste, M., Bell, L., Findlay, I., Findlay, L., \& Henderson, J. (2005). Thinking place: animating the Indigenous humanities in education. The Australian Journal of Indigenous Education, 34, 7-18. https://doi.org/10.1017/S1326011100003926

Barad, K. (2003). Posthumanist performativity: Toward an understanding of how matter comes to matter. Signs, 28(3), 801-831. https://doi.org/10.1086/345321

Britzman, D. P. (2003). Practice makes practice: A critical study of learning to teach (Revised ed.). Albany: State University of New York Press.

Bohm, D. (1996). On dialogue. New York: Routledge. https://doi.org/10.4324/9780203180372

Butler, J. (2010). Frames of war: When is life grievable? Brooklyn: Verso.

Cajete, G. (1994). Look to the mountain: An ecology of Indigenous education. Skyland, NC: Kivaki Press.

Cajete, G. (1999). Igniting the sparkle: An Indigenous science education model. Durango, CO: Kivaki Press.

Denzin, N. K. (2008). Emancipatory discourses and the ethics and politics of interpretation. In N. K. Denzin \& Y. S. Lincoln (Eds.), Collecting and interpreting qualitative materials (3rd ed., pp. 435472). Thousand Oaks, CA: Sage.

Donald, D. (2012). Indigenous métissage: a decolonizing research sensibility. International Journal of Qualitative Studies in Education, 25(5), 533-555. https://doi.org/10.1080/09518398.2011.554449

Ermine, W. (2007). The ethical space of engagement. Indigenous Law Journal, 6(1), 193-203.

Haig-Brown, C. (2008). Taking Indigenous thought seriously: A rant on globalization with some cautionary notes. Journal of the Canadian Association for Curriculum Studies, 6(2), 8-24.

Halberstam, J. (2011). The queer art of failure. Durham and London: Duke University Press. https://doi.org/10.1215/9780822394358

Haraway, D. (2004). The Haraway Reader. New York: Routledge.

Higgins, M. (2011). Finding points of resonance: Nunavut students' perceptions of science. in education, $17(3)$.

Higgins, M. (2014a). De/colonizing pedagogy and pedagogue: Science education through participatory and reflexive videography. Canadian Journal of Science, Mathematics and Technology Education, 14(2), 154-171. https://doi.org/10.1080/14926156.2014.903321

Higgins, M. (2014b). Rebraiding photovoice: Putting to work Indigenous conceptions of praxis and standpoint theory. Australian Journal of Indigenous Education, 43(2), 208-217. https://doi.org/10.1017/jie.2014.18

Higgins, M. (2016). Decolonizing school science: Pedagogically enacting agential literacy and ecologies of relationships. In C. Taylor \& C. Hughes (Eds.), Posthuman Research Practices (pp. 267-289). Basingstoke, UK: Palgrave Macmillan. https://doi.org/10.1057/9781137453082 12

Higgins, M., Madden, B., \& Korteweg, L. (2015). Witnessing (the lack of) deconstruction: White teachers' 'perfect stranger' position in urban Indigenous education. Race Ethnicity and Education, 18(2), 251-276. https://doi.org/10.1080/13613324.2012.759932

Higgins, M. \& Madden, B. (in press). (Not Idling at) the flâneur in Indigenous education: Towards being and becoming community. In R. Irwin \& L. Cutcher (Eds.), Movement as method/practice/praxis: The 'not so idle flâneur'. New York, NY: Palgrave Pivot.

Jackson, A. Y., \& Mazzei, L. (2012). Thinking with theory in qualitative research: Viewing data across multiple perspectives. New York: Routledge. 
Jackson, A., \& Mazzei, L. (2014). Thinking with theory in qualitative research 2.0: The ontological turn and new empiricisms. Workshop at the 10th International Congress of Qualitative Inquiry (ICQI), Urbana-Champaign, IL.

Kirkness, V. J., \& Barnhardt, R. (1991). First Nations and higher education: The four Rs - respect, relevance, reciprocity, responsibility. Journal of American Indian Education 30(3), 9-16.

Kovach, M. (2009). Indigenous methodologies: Characteristics, conversations, and contexts. Toronto: University of Toronto Press.

Kuokkanen, R. (2007). Reshaping the university: Responsibility, Indigenous epistemes, and the logic of the gift. Vancouver: UBC Press.

Kuntz, A. M., \& Presnall, M. M. (2012). Wandering the tactical: From interview to intraview.Qualitative Inquiry, 18(9), 732-744. https://doi.org/10.1177/1077800412453016

Lutrell, W. (2010). 'A camera is a big responsibility': a lens for analyzing children's visual voices. Visual Studies, 25(3), 224-237. https://doi.org/10.1080/1472586X.2010.523274

MacLure, M. (2013). Classification or wonder? Coding as an analytic practice in qualitative research. In B. Coleman \& J. Ringrose (Eds.), Deleuze and research methodologies (pp. 164-183). Edinburgh, UK: Edinburgh University Press.

Madden, B., Higgins, M., \& Korteweg, L. (2013). "Role models can't just be on posters": Re/membering barriers to Indigenous community engagement. Canadian Journal of Education, 36(2), 211-247.

Madden, B. (2017). Tracing spectres of whiteness: Discourse and the construction of teaching subjects in urban Aboriginal education. Discourse: Studies in the Cultural Politics of Education, 38(5), 642658. https://doi.org/10.1080/01596306.2015.1127211

Marker, M. (2004). Four r's revisited: Some reflections on First Nations and higher education. In L. Andres, \& F. Finlay (Eds.), Student affairs: Experiencing higher education (pp. 171-188). Vancouver: UBC Press.

Marin, A. M. (2013). Learning to attend and observe: Parent-child meaning making in the natural world (Unpublished doctoral dissertation). Northwestern University, Illinois.

McGloin, C. (2009). Considering the work of Martin Nakata's "cultural interface": a reflection on theory and practice by a non-Indigenous academic. The Australian Journal of Indigenous Education, 38, 36-41. https://doi.org/10.1375/S1326011100000570

McGregor, H.E. (2015). Decolonizing the Nunavut school system: Stories in a river of time (Unpublished doctoral dissertation). The University of British Columbia, Vancouver.

McGregor, H.E., \& Marker, M. (in press). Reciprocity in Indigenous educational research: Beyond compensation, towards decolonizing. Anthropology and Education Quarterly, 49(3).

McKinley, E. (2007). Postcolonialism, Indigenous students, and science education. In S.K. Abell \& N.G. Lederman (Eds.), Handbook of research on science education (pp. 199- 226). Mahwah, NJ: Lawrence Erlbaum.

Nakata, M. (2007a). Disciplining the savages: Savaging the disciplines - Exploring inscriptions of Islanders in Western systems of thought. Australia: Aboriginal Studies Press.

Nakata, M. (2007b). The cultural interface. The Australian Journal of Indigenous Education, 36, 7-14. https://doi.org/10.1017/S1326011100004646

Ostertag, J. (2015). School gardening, teaching, and a pedagogy of enclosures: Threads of an arts-based métissage (Unpublished doctoral dissertation). The University of British Columbia, Vancouver.

Sedgwick, E. (2003). Touching feeling: Affect, pedagogy, performativity. Durham: Duke University Press.

Simon, R. I. (2006). The pedagogical insistence of public memory. In P. Seixas (Ed.), Theorizing historical consciousness (pp. 183-201). Toronto, Canada: University of Toronto Press.

St. Pierre, E. A. (1997). Methodology in the fold and the irruption of transgressive data. International Journal of Qualitative Studies in Education, 10(2), 175-189. 
Sundberg, J. (2014). Decolonizing posthumanist geographies. Cultural Geographies, 21(1), 33-47. https://doi.org/10.1177/1474474013486067

Trainor, A., \& Bouchard, K. A. (2012). Exploring and developing reciprocity in research design. International Journal of Qualitative Studies in Education, iFirst, 1-18. https://doi.org/10.1080/09518398.2012.724467

Tuck, E., \& Yang, K. W. (2012). Decolonization is not a metaphor. Decolonization: Indigeneity, Education \& Society, 1(1), 1-40. http://decolonization.org/index.php/des/article/view/18630/15554

Wang, C. \& Burris, M. (1997). Photovoice: Concept, methodology and use for participatory needs assessment. Health Education and Behaviour, 24, 369-387. https://doi.org/10.1177/109019819702400309

Whatmore, S. (2006). Materialist returns: Practising cultural geography in and for a more-than- human world. Cultural Geographies, 13, 600-609. https://doi.org/10.1191/1474474006cgi377oa

Yahgulanaas, M. N. (2009). Red: a Haida Manga. Vancouver, BC: Douglas \& McIntyre. 